\title{
Research on Co-evolution of the Ecosystem of Brands-—Based on YanTai Grape Wine Investigation
}

\author{
Aihua Xiong a , Han Zhang ${ }^{b}$, Zhao Han ${ }^{\mathrm{c}}$ \\ Shandong University of Finance and Economics, Jinan, Shandong, 250014, China. \\ a Xiongscxah10@sina.com, b hannah0211@163.com, chuangdaohz@126.com
}

\begin{abstract}
Keywords: Yantai Grape Wine, Branding ecosystem, coordinated development, symbiotic stage.
\end{abstract}
\begin{abstract}
Coordinated development in between main parts of the branding ecosystem is great significance in improving brand economy and regional economy. As Yantai's grape wine branding has developed for over hundreds years of history, the branding ecosystem has progressively formed to brand-centric integrating with the ecosystem in regional economy, politics and culture. This article based on the investigation in Yantai's wine industry sighting in lateral evolution of collaborative system, analyzing the existing problems in Yantai's grape wine branding system, and then constructing a coordinated development model in the branding ecosystem, which is in order to discover the relatively countermeasure for symbiotic stage in the evolution of coordinated development ecosystem.
\end{abstract}

\section{Introduction}

Alone with the intense competition in globalization trend in economic development, regional branding development and refining branding benefits are significantly important for healthy growth in region and even national economy. Branding ecosystem is built on regional brands, brands, local government and external environment. It constitutes a complex economic system, which is coordinated and developed together in many main subjects and subsystems. Coordinated development in branding ecosystem is able to impulse the main business growth and economic prosperity within the system. Yantai is the birthplace of our national wine industry, and is also our largest wine business industrial base. Because its long and rich history, exceptional geometrical environment, fully developed industrial clusters, completed industrial chains, strong scientific and technological strength, and branding cooperative competition, Yantai Grape Wine as an regional brand has its fame nationally and internationally through its branding ecosystem construction. According to Yantai Grape Wine branding ecosystem's construction and its development path, the article will discover branding ecosystem's coordinated development and its countermeasures.

\section{Review of the Related Theory of Brand Ecosystem}

The brand ecosystem is business ecosystem in which brands are compounded with their survival and development environment. It is also an Artificial ecosystem that composed of brands and brand products, brand owners, shareholders, suppliers, end-customer middlemen, competitors, financial institutions, the mass media, the government, the public, related corporations and brand ecological environment (Including social, economic, cultural, natural environment). Domestic and foreign scholars have done lots of literatures on the brand ecosystem. George firstly proposed the concept of ecosystem in 1935 and Promote people to use a new perspective: organic, contact, systematic point of view to understand the world. Agnieszka (1999) discussed the concept and management issues of brand ecological environment and pointed out that the brand ecological environment is a complex, dynamic and evolving organic organization. Yin Hongchun (2005) explained the essence, process and mechanism of competition and cooperation among brand species by using ecology and complex system theory, then she constructed the brand-economy coordination degree evaluation model of the brand ecosystem. Wang Qiwan and Wang Xingyuan (2013) constructed the ecosystem of cluster brands in strategic emerging industries through empirical research, which was consisted of 8 categories and 33 key elements. Li Mingwu and Qi Dan (2017) pointed out that the formation and 
development process of industrial cluster brand ecosystem was the process which depended on the self-adaptive, self-coordinating and self-organizing synergistic evolution of system members. Lu Pengfei and He Hongquan (2016) constructed the co-evolving model of industrial cluster brand and external environment; they also studied the synergistic evolution mechanism between enterprises and environment in the brand ecosystem of industrial cluster. Dang Xiaolan (2016) argued that the brand ecosystem was consist of three levels: the internal brand ecosystem, the stakeholders and the external macro environment and described main features of the brand ecosystem such as integrity, selforganization and co-evolution. Shan Jun (2016) Used grounded theory to take tea regional brand as an example and analyzed the evolution path of regional brand ecosystem and provided the expansion direction for the government and enterprises. Weng Shengbin and Li Yong (2016) found that the gene's robustness, population growth and environmental adaptability have a great impact on the growth of agricultural products brand system.

\section{Co - evolution Analysis of Brand Ecosystem}

The paper base on the composition of the brand ecosystem and presents the evolution of the brand ecosystem as the competition and cooperation, migration and mergers among brand species, and finally achieve from the industrial agglomeration, brand synergy to the synergy of the brand ecosystem. The process of coordinated development can be alienated into four different stages: noninterfering stage, interfering stage, involvement sharing stage and symbiosis stage.

\subsection{Research on Coordinated Development of Yantai Wine Brand Ecosystem}

Yantai is warm temperate continental monsoon climate; it has superior climatic environment and high-quality soil, so that lays a good foundation for the formation of Yantai wine brand. Up to now, as China's largest wine industry base,there are a total of 132 wine production enterprises, 37 largescale enterprises, 14 wineries built or under construction.

(1) Non-interfering stage: Self-organizing synergy

Yantai wine industry has been gradually developed From 1892, when patriotic overseas Chinese Mr.Zhang Bishi founded the first wine brewing enterprise in-Changyu. The main feature of this stage is the emergence of single corporate brands, mostly depend on Changyu brand, and the product is relatively simple, mainly brandy and red wine. There were less business competitors, and the products basically had no difference, both enterprises and brand were in the state of no interfere.

(2) Interfering stage: Coordination with completion

This stage is from the founding of New China to the end of 2000. During this period, the number of wine producers began to increase, brand companies gradually formed. However, With the rapid expansion of the market and fierce competition, the wine producers mostly focused on competition with other companies, and had mutual abuse, malicious acquisition and so on. The characteristic of this stage is that some enterprises begin to awaken their awareness of product brand and product brands begin to increase, and they competed with each other and the niche overlap degree of their brands was high.

(3) Involvement sharing stage and symbiosis stage

From the beginning of this century, Yantai wine industry has entered a period of rapid development, there were lots of emergence of enterprises and product brands and more frequent cooperation, the local government began to actively create a Yantai wine brand overall image. The characteristic of this stage is that Wine brand gathered the brand companies use their own core resources ability to do product positioning and get from the homogenization. Enterprises began to complementary with each other from competition, all small and medium enterprises and product brands promoted cluster brand formation together.

\subsection{The Problems During Ecosystem Evolution Process}

(1) Poor quality of raw materials. The pros and cons of wine quality depend largely on the ripeness of grapes in the producing areas. The grapes harvested by local enterprises cannot meet the quality requirements of producing high-quality wines, greatly reducing the quality of Yantai wines. 
(2) Homogeneous competition is serious. Most companies stick to the original corporate strategy and did not adopt a diversified and differentiated strategy to win the market.

(3) Insufficient investment in capital and technology. There is not enough investment in science and technology for grape growing and wine making technology on Yantai wine brands. Professional and technical personnel of Planting, brewing, management cannot meet the needs of the rapid development of the industry.

(4) Lack of government support. The government, as the guide to controlling local economy and business development, lacks promotion in the promotion of Yantai Wine City, and either little support for the establishment of basic facilities, the introduction of talents and the financial fund. And government have done less policy documents to bound the entire industry market norms and product quality norms.

\section{Symbiotic Evolution Strategy of Brand Ecosystem}

\subsection{Coordination Between the Production Enterprise and the Supplier}

The long-term corporation between the wine producer and the raw material supplier should be enhanced. The wine company should ensure the benefit maximization for the orchardist in order to reach an agreement with the supplier. Meanwhile, it is significant to encourage the wine companies to establish their own raw material base, which follows the principle including unified standard, technique, management and relatively centralization. In addition, the improvement of the scale and the standardization will be helpful to raw material base development.

\subsection{Coordination Between the Competitors}

Corporations within the same industry should create the cooperation relationship, which is designed to achieve both marketing and innovation synergies. Additionally, with thesupport from colleges, universities, scientific research institutes and industry organizations in Yantai, a strategy group within the wine industry can be formed, aiming to develop basic and applied research based on raw material growing as well as standardization and scientific management. Moreover, it is necessary to speed the operational mechanism development, which will provide benefits for technological innovation and commercialization of research findings. Further, the ratio of high-range wine, midrange wine and table wine should be adjusted by the leading enterprises to achieve a wider variety. There are several requirements of the leading enterprise, including taking social responsibilities, strengthening self-discipline, showing leadership within the industry and guiding the direction of the industry development. As for the brand image, companies may focus on protecting trademark and intellectual property sharply, improve the brand effect and therefore enhance the market share through customer loyalty. Meanwhile, in order to maintain the reputation, create fair, orderly and win-win cooperation market in the wine industry, companies are supposed to advocate integrity management, build credit rating agencies and effective castigation mechanism of breaking faith.

\subsection{Coordination Between the Government and the Enterprise}

\section{(1)Talent strategy}

It could be effective for the government to encourage local enterprise to communicate with wine industry leaders overseas. As a result, domestic companies will take advantage of government's bridging role to implement staff training, promote the establishment of public service platform, and develop production techniques and marking strategy. In this way, both employees' professional skills and companies' sustainable development could be improved.

(2)Culture propaganda through government and enterprise cooperation

Based on government support, it is possible for the enterprise to establish a comprehensive wine Culture and Expo Centre with the purpose of introducing wine culture and featured wine products by collection display, culture promotion and tasting experiences. In addition, the strategy can also be achieved through excavating wine cultural connotation, planning visitor routes scientifically and attracting more visitors to engage in the wine culture tourism project. On the other hand, new marking and promotion models, such as various media organizations, websites, wine festivals and important 
national meetings, e-commerce as well as Things of Internet, will also assist in building the overall brand image of Yantai wine.

(3) Special funds and credit strategies. The government should set up a special fund for the development of wine industry, which is mainly used to support the construction of wine grape bases and the overall brand building of Yantai wine.

As the figure 2, through the implementation of the above various synergistic strategies, a harmonious ecosystem will surely be established between enterprises and enterprises, between enterprises and governments, between enterprises and universities, between enterprises and society.

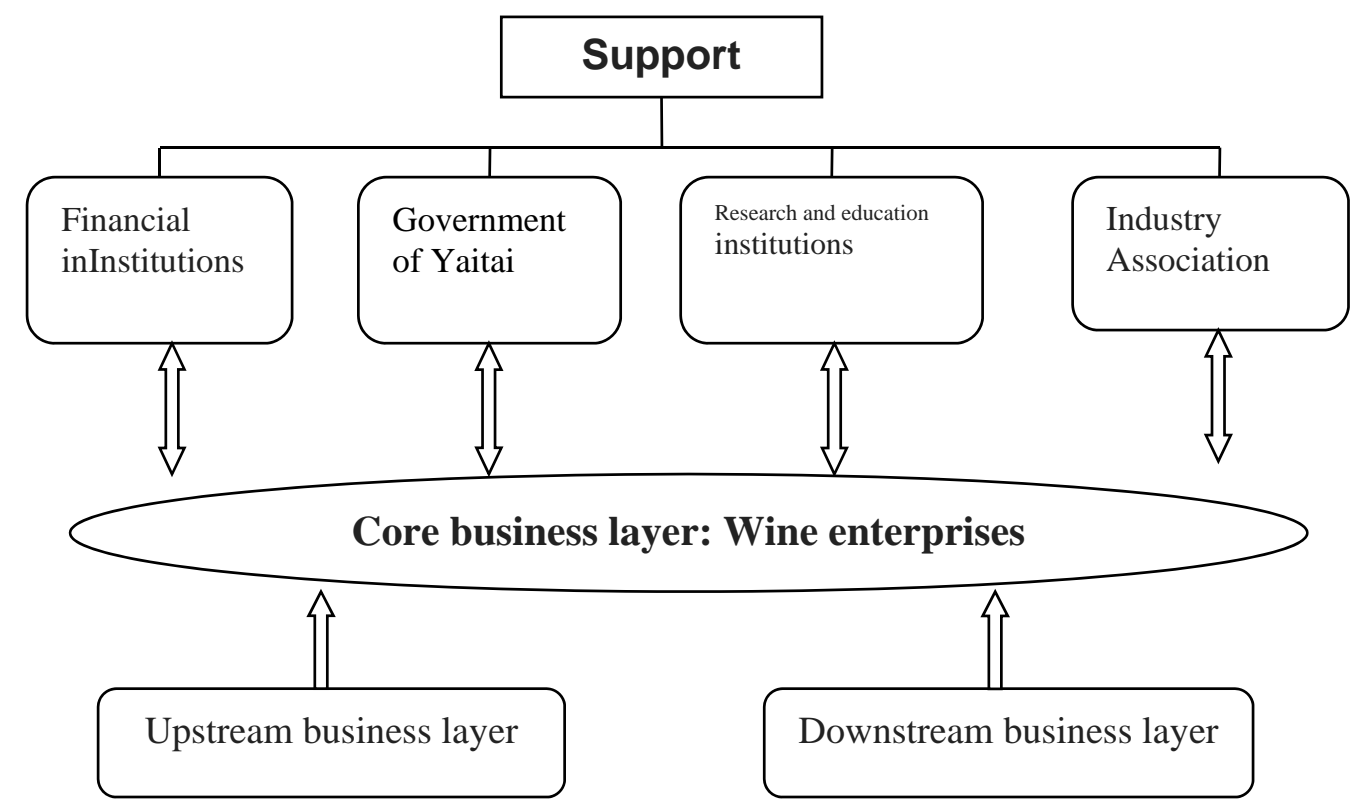

Fig. 1. harmonious ecosystem of Yantai Grape Wine

\section{References}

[1]. Aaker D A, Joachimsthaler E. Brand Leadership - Building Assets in an Information Economy[J]. Free Pr, 2009.

[2]. Winkler B A. Warp-Speed Branding: The Impact of Technology on Marketing [M]. Wiley, 1999,P137-139.

[3]. Sun Chengzhang. Introduction to Modern Business Ecology. Beijing: Economic Management Press, 1996

[4]. Yin Hongchun. Research on the complex adaptability and co-evolution of brand ecosystems: Dissertation of Tianjin University, 2005

[5]. Wang Qiwan, Wang Xingyuan. Research on Brand Ecosystem of Strategic Emerging Industrial Clusters[J]. Research Management, 2013, V34(10):153-160.

[6]. Wang Qiwan, Zhu Hong, Wang Xingyuan. Research on Cluster Brand Driving Mechanism under the Framework of Brand Ecosystem[J]. Economic Management Research, 2015(1):132-138.

[7]. Mingwu Li, Dang Dan. The composition, characteristics and evolution of industrial cluster brand ecosystem[J]. Business Economics, 2017(3):23-28. Xiong Aihua. Co-evolution of Brand Ecosystems: Economic Science Press, 2012 
[8]. Lu Pengfei, He Hongquan. Research on Cooperative Mechanism and Operation Mechanism of Brand Ecosystem in Industrial Clusters[J]. Industrial Technology \& Economy, 2016, 35(11):102108.

[9]. Dang Xiaoyi. Analysis of Brand Construction Based on Brand Ecosystem[J]. Chinese Journal of Value Engineering, 2016, 35(26).

[10]. Shan Jun, Jiang Hanchun, Xu Weijian. An analysis of the evolution path of regional brand ecosystem of agricultural products based on grounded theory-Taking tea regional brand as an example[J]. Journal of Anhui Agricultural University, 2016, 25(3):20- 28.

[11]. Weng Shengbin, Li Yong. Research on the Growth of Regional Brand Ecosystem in Agricultural Products[J]. Agricultural Technology \& Economy, 2016(2): 113-119 